\title{
Rate and Associated Factors of Discontinuation of Anti-Tuberculosis Treatment in Patients with Pulmonary Tuberculosis at Positive Microscopy in the City of Mbuji Mayi, DR Congo
}

\author{
—Case of the HDTC of Muya and Lubilanji Health Zones
}

\author{
André Kazadi Mukendi ${ }^{1}$, Jean Christophe Bukasa Tshilonda ${ }^{1}$, Jean René Mukendi Mukendi' \\ Robert Ntumba Cilumba ${ }^{1}$, André Kabamba Mutombo ${ }^{2}$, Marcel Kazadi Nsenda ${ }^{3}$, \\ Stany Wembonyama Okitotsho ${ }^{4}$
}

\author{
${ }^{1}$ Higher Institute of Medical Techniques of Mbujimayi, Mbujimayi, DR Congo \\ ${ }^{2}$ Official University of Mbujimayi, Mbujimayi, DR Congo \\ ${ }^{3}$ Provincial Coordination of Leprosy and Tuberculosis of Kasai Oriental, Mbujimayi, DR Congo \\ ${ }^{4}$ School of Public Health, University of Lubumbashi, Lubumbashi, DR Congo \\ Email: jcbukasa4@gmail.com
}

How to cite this paper: Mukendi, A.K., Tshilonda, J.C.B., Mukendi, J.R.M., Cilumba, R.N., Mutombo, A.K., Nsenda, M.K. and Okitotsho, S.W. (2020) Rate and Associated Factors of Discontinuation of Anti-Tuberculosis Treatment in Patients with Pulmonary Tuberculosis at Positive Microscopy in the City of Mbuji Mayi, DR Congo-Case of the HDTC of Muya and Lubilanji Health Zones. Open Access Library Journal, 7: e6704.

https://doi.org/10.4236/oalib.1106704

Received: August 11, 2020

Accepted: September 27, 2020

Published: September 30, 2020

Copyright $\odot 2020$ by author(s) and Open Access Library Inc.

This work is licensed under the Creative Commons Attribution International License (CC BY 4.0).

http://creativecommons.org/licenses/by/4.0/ (c) $\underset{\mathrm{BY}}{\mathrm{i}}$ Open Access

\begin{abstract}
Introduction: the objective of this work was to contribute to the improvement of the management of tuberculosis and to the reduction of the rate of abandonment of the anti-tuberculosis treatment by the determination of the associated factors in the city of Mbuji-Mayi. Method: the study is quantitative, it is kind of descriptive correlational. The sample is non-probabilistic of the accidental type, the size of which is $\mathbf{3 6}$ subjects. Results: 1) About the rate of discontinuation of anti-tuberculosis treatment: Our results CON anoint that of the total of $\mathbf{3 0 2 9}$ tuberculosis patients who visited the health structures of these two health zones, 36 had discontinued treatment, a rate of $1.18 \%$. On 36 cases of abandonment, 9 cases (or 25\%) had resumed treatment and 27 cases (75\%) had completely abandoned. 2) A Factors associated with total discontinuation of treatment: The association between total abandonment of treatment and more variables of our study revealed that the middle of transport ( $\chi^{2} 21.9440, \mathrm{p}$ 0.049), consideration of the dignity of the per ringing in taking load ( $\left.\chi^{2} 254357, \mathrm{p} 0.019\right)$ and the number of the tablets as a result of abandonment $\left(\chi^{2}\right.$ 5.4152, $\mathrm{p}$ 0.019) are associated with the total abandonment of TB treatment. Conclusion: Despite all the concerted efforts to reduce the burden of tuberculosis, the latter remains globally significant. Strengthening health systems for early detection of tuberculosis and improving the quality of tuber-
\end{abstract}


culosis care, including rapid and accurate diagnosis, early initiation of treatment and regular monitoring, are priorities. Countries with higher TB rates than expected for their level of socio-demographic development should study not only the reasons for late consultation of TB patients, but also those related to the problem of discontinuing treatment and take corrective action.

\section{Subject Areas}

Nursing

\section{Keywords}

Tuberculosis, Rates, Abandonment, Anti Tuberculosis, Positive Microscopy

\section{Introduction}

Tuberculosis is a major global public health problem [1]. Each year, there are approximately 9 million new cases and nearly 2 million people die from this disease [2].

In 2015, the WHO [3] estimated the number of new cases (incidents) of tuberculosis at 10.4 million worldwide, including 5.9 million (56\%) in men, 3.5 million (34\%) in women and 1 million (10\%) in children. People living with HIV accounted for 1.2 million (11\%) of all new TB cases. Tuberculosis notification rates are 5 to 81 times higher in prisons around the world than in the general population [4].

Without treatment, the death rate is very high (up to $70 \%$ death within 10 years of infection in uninfected patients with HIV with sputum positive on microscopic examination), but the combination of drugs TB for years 1950 has helped dramatically reduce the mortality rate of the tuberculose [5].

Adherence to long-term treatment for tuberculosis is a complex phenomenon with a wide range of factors impacting therapeutic behavior. Failure to process defect is detrimental for both the patient and the community, with a higher risk of relapse [6].

The DRC, like any other low-income country, is not spared by this situation. In our country, tuberculosis is a disease that carries a heavy economic and social burden, and nearly 120,000 cases are reported each year. The DRC is among the twenty-two countries that bear eighty percent of the global burden of tuberculosis in general and is also among the twenty-seven countries with eighty-five percent of the global burden of disease, with regard to multidrug resistant tuberculosis. In 2014, the DRC with an estimated population of 72,505,278 inhabitants, it had an incidence of tuberculosis cases of all forms of 327 cases per 100,000 inhabitants [7].

In view of all these data so convincing that tuberculosis remains a major public health problem both internationally and nationally and more particularly in our communities where the dropout rate is not negligible, we have decided to 
conduct a study relating to the determination of the rate and the factors associated with the total abandonment of anti-tuberculosis treatment in the HDTC of the MUYA and LUBILANJI Health Zones of the city of Mbuji-Mayi.

\section{Material and Method}

Our study is quantitative, it is kind of descriptive correlational whose purpose is to determine the rate and the factors associated with the abandonment of the very treatment TB in Zones Lubilanji and health Muya.

The target population consists of TB patients has bandonnés treatment in re making structures in charge of Zones health and Lubilanji Muya, during the period from January 01, 2013 to December 31, 2017.

To mount the study sample, we use the non-accidental probability sampling technique that involves taking the data available for the period of our investigation and the size rises to 36 subjects and this on basis of the selection criteria below:

\section{1) Inclusion criteria for the case}

- Being sick having abandoned anti-tuberculosis treatment in one of the HDTC of these two ZS;

- Be available on the day of data collection;

- Accept to participate voluntarily in the study;

- Have your file in the care structure with a clearly identifiable address.

\section{2) Exclusion criterion}

- Any patient who did not meet the criteria mentioned above.

The questionnaire and the literature review were used to collect data and record factual information. Thus, the data from the collection sites, recorded on the collection tools by the investigators were compiled, cleaned and then codified by creating new variables by the analyst. These data have been inputs with the EXCEL 2007 and operated by the EPI-INFO software Version 7.1.1.1. In bivariate analysis, we crossed the independent variables with the dependent variable to determine the link between them.

The results of this study have been estimated at a confidence interval (CI) of $95 \%$ the risk of error alpha set at $5 \%(\mathrm{p}=0.05)$. These results are presented in the form of commented tables and figures.

\section{Results}

\subsection{Results Descriptive Analyzes}

Table 1 shows the number of tuberculosis cases compared to dropouts from 2012 to 2018 in the HDTC of the MUYA and LUBILANJI health zones.

Figure 1 shows that out of the total of 3029 tuberculosis patients who attended the HDTC in these two health zones from 2013 to 2017, 36 patients had abandoned treatment, i.e. a rate of $1.18 \%$.

Figure 2 tells us that among the dropouts, 9 cases (or 25\%) had resumed treatment and the 27 cases (or $75 \%$ ) had completely abandoned treatment. 
A. K. Mukendi et al.

Table 1. Breakdown of the number of tuberculosis cases compared to dropouts from 2012 to 2018 in the HDTC of the MUYA and LUBILANJI health zones.

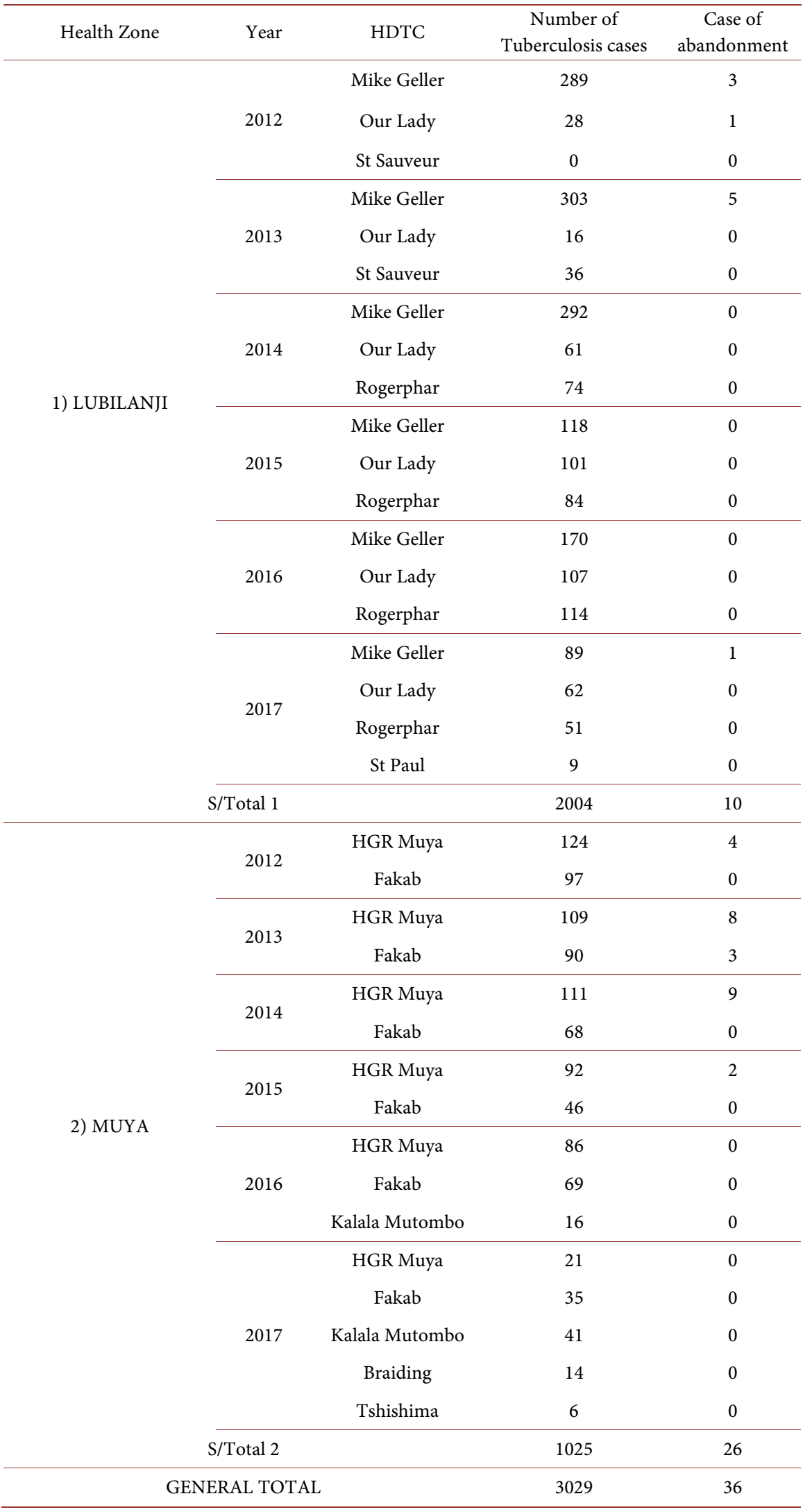




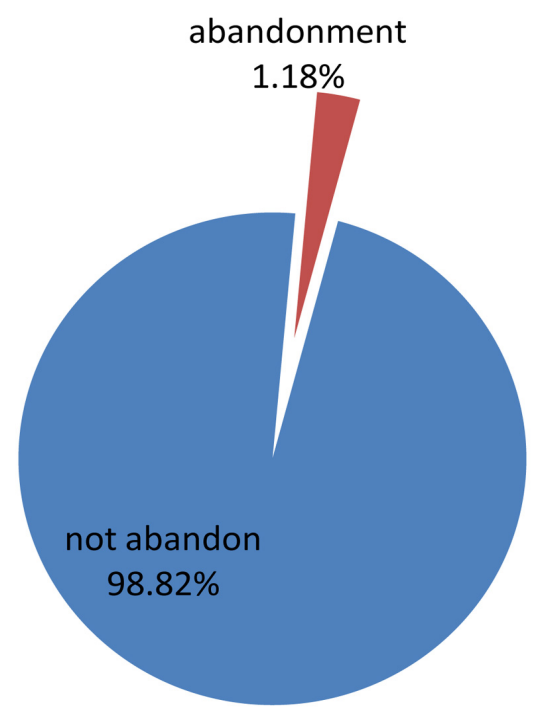

Figure 1. Rate of discontinuation of anti-tuberculosis treatment.

\section{Discontinuation of treatment}

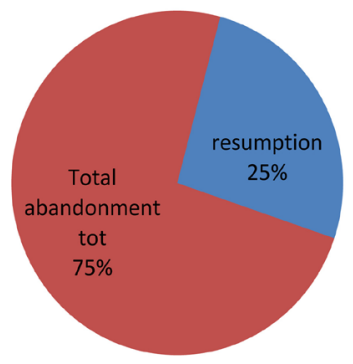

Figure 2. Distribution of respondents according to the modality of abandonment of treatment after interruption.

In Table 2, we see that the age group of 18 and over is more represented with $75 \%$, but overall the average age is $30+-16.1$ years. In relation to sex, women are predominant with $58.3 \%$. The majority are employed (77.8\%), with marital status dominated by $47.2 \%$ of Singles. Most of them have a primary level of education calf, $34.3 \%$ and $55.6 \%$ of our respondents come from ZS Muya. The majority of respondents are non-smokers, i.e. $80.6 \% .61 .1 \%$ are not used to taking other toxic substances such as alcohol, psychotropic drugs and hemp. There was 69.5\% absence of HIV co-infection.

In view of Table 3, we note that in general the patients appreciated that the reception was satisfactory in $55.5 \%$ of cases, the waiting time before the consultation seemed long for the patients (30 min and more) with satisfactory consultation in $52.8 \%$.

$75.0 \%$ of patients had no difficulty in communicating with healthcare providers, $88.8 \%$ approve of the existence of the posters talking about TBC and $63.9 \%$ the understanding of the messages transmitted, but explanations on the benefits of mandatory supervision treatment seemed to be neglected (55.5\%). 
Table 2. Distribution of respondents according to socio-demographic characteristics and factors linked to the patient.

\begin{tabular}{|c|c|c|c|}
\hline Feature & Categories & $\begin{array}{c}\text { Workforce } \\
n=36\end{array}$ & $\%$ \\
\hline \multirow{2}{*}{$\begin{array}{l}\text { Age } \\
\text { Average age }\end{array}$} & Under 18 & 9 & 25 \\
\hline & $\begin{array}{l}18 \text { years and over } \\
30+-16.1 \text { years }\end{array}$ & 27 & 75 \\
\hline \multirow{2}{*}{ Sex } & Male & 15 & 41.7 \\
\hline & Female & 21 & 58.3 \\
\hline \multirow{2}{*}{ Occupation } & Without occupation & 8 & 22.2 \\
\hline & With occupancy & 28 & 77.8 \\
\hline \multirow{3}{*}{ Maritalstatus } & Married & 15 & 41.7 \\
\hline & Single & 17 & 47.2 \\
\hline & Widowerwidow & 4 & 11.1 \\
\hline \multirow{2}{*}{ Residence } & ZsLubilanji & 16 & 44.4 \\
\hline & ZsdelaMuya & 20 & 55.6 \\
\hline \multirow{4}{*}{ Educational level } & Without level & 6 & 16.7 \\
\hline & Primary & 13 & 36.1 \\
\hline & Secondary & 9 & 25.0 \\
\hline & Superior & 8 & 22.2 \\
\hline \multirow{2}{*}{ Smoking } & Smoking & 7 & 19.4 \\
\hline & Non-smoker & 29 & 80.6 \\
\hline \multirow{2}{*}{ Othertoxichabits } & Yes (alcohol, psychotropic drugs and hemp & 14 & 38.9 \\
\hline & No & 22 & 61.1 \\
\hline \multirow{2}{*}{ HIV co-infection } & Yes & 11 & 30.5 \\
\hline & No & 25 & 69.5 \\
\hline
\end{tabular}

Table 3. Distribution of respondents according to factors related to healthcare providers.

\begin{tabular}{lccc}
\hline \multicolumn{1}{c}{ Factors } & Categories & $\begin{array}{c}\text { Workforce } \\
\mathbf{n}=36\end{array}$ & $\%$ \\
\hline Appreciation of the welcome & Satisfactory & 20 & 55.5 \\
& Not satisfying & 16 & 44.5 \\
Waiting time before & Less than 30 min & 17 & 47.2 \\
consultation & 30 min and more & 19 & 52.8 \\
& Less than 30 min & 19 & 52.8 \\
Duration of consultation & 30 min and more & 17 & 47.2 \\
& Satisfactory & 21 & 58.3 \\
Assessment of the consultation & Unsatisfactory & 15 & 41.7 \\
& & & \\
Communication difficulty & Yes & 9 & 25.0 \\
& No & 27 & 75.0 \\
Existence of TBC posters & Yes & 32 & 88.8 \\
Understanding the messages & No & 4 & 11.2 \\
transmitted & Yes & 23 & 63.9 \\
Explanation of the benefit of & No & 13 & 36.1 \\
mandatory Q3 supervision & Yes & 20 & 55.5 \\
\hline
\end{tabular}


In Table 4, we see that $100 \%$ of patients walked a distance of less than $5 \mathrm{~km}$ between their home and the HDTC, $94.4 \%$ of patients made their way to receive the drugs, $75.0 \%$ say there was no drug out-of-stock, $100 \%$ of patients are not hospitalized were to die purpose of treatment, $69.4 \%$ say that there were mismatches between the time of decisions medicaments and their programs, the waiting time before taking medications $\mathrm{fl}$ is unsatisfactory for $61.1 \%$ of the patients, and they waited before taking medicines to inappropriate place $(77.8 \%)$, $52.8 \%$ of patients had the feeling of being treated with dignity and $75.0 \%$ of patients have not solicited by the providers after discontinuation.

\subsection{Bi-Varied Analysis Results}

Table 5 shows that the association of sociodemographic characteristics and treatment discontinuation revealed no difference significantly.

From Table 6, we can see that there is no association between the factors related to the provision of care and the discontinuation of anti-tuberculosis treatment.

As shown in Table 7, the association between the organization of health services and total abandonment of treatment reveals that the Means of transport used ( $\chi^{2} 21.9440 ; \mathrm{p}$ 0.049) and the consideration of the dignity of the person in the care $\left(\chi^{2}\right.$ 5.4357; $\mathrm{p}$ 0.019) are associated with total discontinuation of anti-tuberculosis treatment.

Table 4. Distribution of respondents according to factors linked to the organization of health services.

\begin{tabular}{|c|c|c|c|}
\hline Factors & Categories & $\begin{array}{c}\text { Workforce } \\
\mathrm{n}=36\end{array}$ & $\%$ \\
\hline \multirow{2}{*}{ Distance between home and HDTC } & Less than $5 \mathrm{~km}$ & 36 & 100 \\
\hline & More than $5 \mathrm{~km}$ & 0 & 0 \\
\hline \multirow{2}{*}{ Means of transport used } & Feet & 34 & 94.4 \\
\hline & Motorbike & 2 & 5.6 \\
\hline \multirow{2}{*}{ Out of stock of drugs } & Yes & 9 & 25.0 \\
\hline & No & 27 & 75.0 \\
\hline \multirow{2}{*}{ Hospitalization at the start of Q3 } & Yes & 0 & 0 \\
\hline & No & 36 & 100 \\
\hline Adequacy of the medication & Yes & 25 & 69.4 \\
\hline schedule and its programs & No & 11 & 30.6 \\
\hline \multirow{2}{*}{$\begin{array}{l}\text { Waiting time before } \\
\text { taking medication }\end{array}$} & Satisfactory & 14 & 38.9 \\
\hline & Unsatisfactory & 22 & 61.1 \\
\hline \multirow{2}{*}{$\begin{array}{l}\text { Waiting area before } \\
\text { taking medication }\end{array}$} & Suitable room & 8 & 22.2 \\
\hline & Inappropriate place & 28 & 77.8 \\
\hline \multirow{2}{*}{ Feeling to be treated with dignity } & Yes & 19 & 52.8 \\
\hline & No & 17 & 47.2 \\
\hline \multirow{2}{*}{ Being solicited after abandonment } & Yes & 9 & 25.0 \\
\hline & No & 27 & 75.0 \\
\hline
\end{tabular}


Table 5. Association between socio-demographic characteristics, patient-related factors and treatment discontinuation.

\begin{tabular}{|c|c|c|c|c|c|}
\hline \multirow{2}{*}{ Feature } & \multicolumn{2}{|c|}{ Total abandonment } & \multirow{2}{*}{$x^{2}$} & \multirow{2}{*}{$\mathrm{p}$} & \multirow{2}{*}{ Meaning } \\
\hline & Yes $n=27$ & No $n=9$ & & & \\
\hline \multicolumn{6}{|l|}{ Age } \\
\hline Under 18 & 07 & 02 & 0.0011 & 0.973 & NS \\
\hline 18 years and over & 20 & 7 & & & \\
\hline \multicolumn{6}{|l|}{ Sex } \\
\hline male & 10 & 05 & 1.0864 & 0.297 & NS \\
\hline feminine & 17 & 04 & & & \\
\hline \multicolumn{6}{|l|}{ Occupation } \\
\hline without occupation & 06 & 02 & 0.5637 & 0.452 & NS \\
\hline with occupation & 21 & 07 & & & \\
\hline \multicolumn{6}{|l|}{ Study level } \\
\hline insufficient & 15 & 02 & 0.1130 & 0.736 & NS \\
\hline sufficient & 12 & 07 & & & \\
\hline \multicolumn{6}{|l|}{ Smoking } \\
\hline smoking & 05 & 02 & 0.1903 & 0.662 & NS \\
\hline non-smoker & 22 & 07 & & & \\
\hline \multicolumn{6}{|l|}{ HIV co-infection } \\
\hline Yes & 06 & 05 & 3.6223 & 0.057 & NS \\
\hline No & 21 & 04 & & & \\
\hline
\end{tabular}

Table 6. Association between factors related to caregiving and treatment discontinuation.

\begin{tabular}{|c|c|c|c|c|c|}
\hline \multirow[t]{2}{*}{ Factors } & \multicolumn{2}{|c|}{$\begin{array}{c}\text { Total } \\
\text { abandonment }\end{array}$} & \multirow[t]{2}{*}{$x^{2}$} & \multirow[t]{2}{*}{$\mathrm{p}$} & \multirow[t]{2}{*}{ SIGN } \\
\hline & Yes $=27$ & No $=9$ & & & \\
\hline \multicolumn{6}{|c|}{ Appreciation of the welcome } \\
\hline Satisfactory & 16 & 05 & 0.5718 & 0.449 & NS \\
\hline Not satisfying & 11 & 04 & & & \\
\hline \multicolumn{6}{|c|}{ Waiting time before consultation } \\
\hline Less than $30 \mathrm{~min}$ & 12 & 05 & 2.8385 & 0.092 & NS \\
\hline $30 \mathrm{~min}$ and more & 15 & 04 & & & \\
\hline \multicolumn{6}{|c|}{ Assessment of the consultation } \\
\hline Satisfactory & 15 & 05 & 0.0065 & 0.935 & NS \\
\hline Unsatisfactory & 12 & 04 & & & \\
\hline \multicolumn{6}{|l|}{ Existence of TBC posters } \\
\hline Yes & 23 & 09 & 1.1863 & 0.276 & NS \\
\hline No & 04 & 00 & & & \\
\hline \multicolumn{6}{|c|}{ Understanding the messages transmitted } \\
\hline Yes & 07 & 02 & 1.1863 & 0.276 & NS \\
\hline No & 20 & 07 & & & \\
\hline \multicolumn{6}{|c|}{ Explanation of the benefit of mandatory } \\
\hline \multicolumn{6}{|c|}{ Q3 supervision } \\
\hline Yes & 15 & 06 & & 0.165 & NS \\
\hline No & 12 & 03 & & & \\
\hline
\end{tabular}


Table 7. Association between factors related to the organization of health services and total discontinuation of treatment.

\begin{tabular}{|c|c|c|c|c|c|}
\hline \multirow{2}{*}{ Factors } & \multicolumn{2}{|c|}{ A total band } & \multirow{2}{*}{$x^{2}$} & \multirow{2}{*}{$\mathrm{p}$} & \multirow{2}{*}{ SIGN } \\
\hline & Yes $=27$ & No $=9$ & & & \\
\hline \multicolumn{6}{|c|}{ Distance between home and childcare center } \\
\hline Less than $5 \mathrm{~km}$ & 21 & 07 & 0.1318 & 0.716 & NS \\
\hline More than $5 \mathrm{~km}$ & 06 & 02 & & & \\
\hline \multicolumn{6}{|l|}{ Means of transport used } \\
\hline Feet & 25 & 04 & 21.9440 & 0.000 & $S$ \\
\hline Motorbike & 02 & 05 & & & \\
\hline \multicolumn{6}{|c|}{ Absence from treatment due to lack of money } \\
\hline Yes & 09 & 04 & 1.1879 & 0.275 & NS \\
\hline No & 18 & 05 & & & \\
\hline \multicolumn{6}{|l|}{ Out of stock of drugs } \\
\hline Yes & 06 & 03 & 1.5603 & 0.211 & NS \\
\hline No & 21 & 06 & & & \\
\hline \multicolumn{6}{|l|}{ Hospitalization at the start of Q3 } \\
\hline Yes & 07 & 05 & 3.8554 & 0.049 & S \\
\hline No & 20 & 04 & & & \\
\hline \multicolumn{6}{|c|}{ Adequacy of the medication schedule and its programs } \\
\hline Yes & 19 & 06 & 0.5485 & 0.458 & NS \\
\hline No & 08 & 03 & & & \\
\hline \multicolumn{6}{|l|}{ Waiting time before taking medication } \\
\hline Satisfactory & 11 & 04 & 0.6265 & 0.428 & NS \\
\hline Unsatisfactory & 16 & 05 & & & \\
\hline \multicolumn{6}{|l|}{ Waiting area before taking medication } \\
\hline Suitable room & 06 & 02 & 0.1318 & 0.716 & NS \\
\hline Inappropriate place & 21 & 07 & & & \\
\hline \multicolumn{6}{|l|}{ feeling of being treated with dignity } \\
\hline Yes & 11 & 07 & 5.4357 & 0.019 & $S$ \\
\hline No & 16 & 02 & & & \\
\hline \multicolumn{6}{|l|}{ To be solicited after abandonment } \\
\hline Yes & 08 & 01 & 2.3415 & 0.1259 & NS \\
\hline No & 19 & 08 & & & \\
\hline
\end{tabular}

\section{Discussion}

\subsection{Results of the Descriptive Analyzes}

\subsubsection{In Relation to the Treatment Abandonment Rate}

Our results show that out of the total of 3029 tuberculosis patients who attended HDTC in these two health zones, 36 patients had abandoned treatment, i.e. a rate of $1.18 \%$. This rate is close to that found in Kinshasa in 2009 by Okenge et al. [8].

In addition, out of 36 cases of discontinuation of treatment, 9 cases (i.e. 25\%) had resumed treatment and the 27 cases (i.e. 75\%) had completely abandoned. Comparing the statements of patients, this is related to patient follow-up, this is how the 9 cases ranks in the proportion of patients who were followed after recognition of their absence to treatment. As the observation made in our study, for 
their part, Hill et al. [9] in The Gambia, had also noted in their study that among the 301 patients, there were 76 discontinuation of treatment (25.2\%); 25 of them did not return for treatment. The dropout rate was higher among those who said they had doubts about the activity of their treatment (HR 3.64; 95\% CI 1.42 9.21; $\mathrm{p}=0.007)$ and among those who had significant costs in time and money to get to their treatment (HR 2.67; 95\% CI $1.05-6.81 ; \mathrm{p}=0.04$ ).

\subsubsection{In Relation to Patient-Related Factors}

The age group 18 and over is more represented with $75 \%$, but overall the average age is $30+-16.1$ years. In relation to sex, women are predominant with $58.3 \%$. The majority are employed (77.8\%), with marital status dominated by $47.2 \%$ of Singles. Most of them have a primary level of education calf, $34.3 \%$ and $55.6 \%$ of our respondents come from ZS Muya. The majority of respondents are non-smokers, i.e. $80.6 \%$. $61.1 \%$ are not used to taking other toxic substances such as alcohol, psychotropic drugs and hemp. There was $69.5 \%$ absence of HIV co-infection.

Contrary to our results, In Morocco, Ikrame Mouhi [10] in his study, the most affected age group is between 20 and 40 years, the male sex is more affected than the female sex; tuberculosis is more common in urban areas than in rural areas; extra-pulmonary involvement is the most frequent.

\subsubsection{Results of Factors Related to Caregiving}

The results show that in general the patients had appreciated that the reception was satisfactory in $55.5 \%$ of cases, the waiting time before the consultation seemed long for patients (30 min and more) with a consultaion satisfactory in $52.8 \%$.

$75.0 \%$ of patients had no difficulty in communicating with health care providers, $88.8 \%$ approve of the existence of the posters talking about TBC and $63.9 \%$ the understanding of the messages transmitted, but explanations on the benefits of mandatory supervision treatment seemed to be neglected (55.5\%). In a survey carried out in the Brazzaville health region among 51 smear-positive pulmonary tuberculosis patients who had abandoned their treatment a few months previously by M’boussa J., Martins H., Adicolle-Metoul J.M., Loubaki F. [11], the author shows that all cultural and economic factors have been sought in the influence of this phenomenon, it appeared that the ignorance of patients is the main cause of abandonment attributable to the latter. The authors nonetheless think that the responsibility is shared because the information-education-communication component of the medical staff and being one of the essential elements of the organization of care, has a not insignificant influence on the abandonment of treatment in general. The best way to reduce the dropout rate which is $11.5 \%$ in Brazzaville is to apply the WHO DOTS strategy.

\subsubsection{Results of Factors Linked to the Organization of Health Services}

In our study, we find that $100 \%$ of patients walked a distance of less than $5 \mathrm{~km}$ between their home and the HDTC, $94.4 \%$ of patients made their way to receive the drugs, $75.0 \%$ say there was no drug out-of-stock, $100 \%$ of patients are not hospitalized were to die purpose of treatment, $69.4 \%$ say that there were mismatches 
between the time of decisions medicaments and their programs, the waiting time before taking medications is unsatisfactory for $61.1 \%$ of the patients, and they waited before taking medicines to inappropriate place (77.8\%), 52.8\% of patients had the feeling of being treated with dignity and $75.0 \%$ of patients have not solicited by the providers after discontinuation. For his part, Lamia Hassani [12], like his fellow Moroccans, he shows that the organization of the health system was dominated by long waiting times (17\%), inaccessibility to the treatment center (16.2\%), insufficient health education, the constraints of treatment supervision (7\%) and insufficient involvement of first-level health personnel.

In addition, Hill et al. [8] in the Gambia found that the dropout rate was higher among those who said they had doubts about the activity of their treatment (HR 3.64; CI 95\% 1.42 - 9.21; $\mathrm{p}=0.007$ ) and in those who incurred significant costs in time and money to get to their treatment (HR 2.67; 95\% CI 1.05 $6.81 ; \mathrm{p}=0.04)$. And the following factors had different effects at different times: The uncertainty about treatment success was significant during the first 90 days of treatment, while an increased cost to get to the polyclinic was significant afterwards 90 days.

Another study conducted in the city of Antananarivo by Julio Rakotonirina et al. [13] supports that living far from the treatment center is correlated with abandonment $(\mathrm{OR}=3.43[1.16 ; 10,15])$. In this perspective of idea, a recent study carried out in Morocco on the risk factors of the abandonment of anti-bacillary treatment in patients with microscopically positive pulmonary tuberculosis (TPM+) by Habibi et al. [14] notes that the factors for abandoning anti-bacillary treatment were the long duration of treatment (53.6\%), too many drugs (48.7\%), the appearance of digestive intolerance (19.5\%) and hepatic (2.4\%), improvement in physical condition (17\%), social problems (12\%), psychological problems (4.8\%), isolation in $9.7 \%$, financial difficulties at $(9.7 \%) ; 63.4 \%$ of patients know that interrupting treatment has risks for them; and only $24.3 \%$ know that this interruption has risks for those around them; 70.7\% are for treatment supervision. Also, Lamia Hassani [11] found that the factors inherent to the treatment were mainly due to the long duration of the treatment, $81.4 \%$ of the patients interviewed had judged that the cause of their abandonment was the long duration of the treatment.

\subsection{Bi-Varied Analysis Results}

The association between the organization of health services and total abandonment of treatment reveals that the Means of transport used ( $\chi^{2} 21.9440 ; p$ 0.049) and the consideration of the dignity of the person in the care ( $\left.\chi^{2} 5.4357 ; \mathrm{p} 0.019\right)$ are associated with total discontinuation of anti-tuberculosis treatment. Unlike a study conducted in our country by Okenge NL, et al. [8], they found in their sampling survey in Kinshasa that the status of single OR 3.173 (1.232 - 11.037), the age below 40 years OR: 1.930 (1.215 - 4.054), ignorance of the etiology of the disease 0R: $20.210(2.358-29.060)$, poor geographical accessibility 0R: 4.500 (1.289 - 15.573) and a poor source of information on the disease 0R: 4.451 (1.740 - 11.338) were factors determining the discontinuation of treatment. 


\section{Conclusion}

Despite all the concerted efforts to reduce the burden of tuberculosis, the burden of the disease remains significant overall. Strengthening health systems for early detection of tuberculosis and improving the quality of tuberculosis care, including rapid and accurate diagnosis, early initiation of treatment and regular monitoring, are priorities. Countries with higher TB rates than expected for their level of socio-demographic development should study not only the reasons for late consultation of TB patients, but also those related to the problem of discontinuing treatment and take corrective action.

\section{References}

[1] Government of India (2009) National Tuberculosis Control Program Revised, Status Report.

[2] WHO (2011) World Tuberculosis Report, Geneva.

[3] WHO (2016) Report on the Fight against Tuberculosis in the World, Geneva.

[4] Medeiros, T.F., et al. (2010) Molecular Epidemiology of Strains of Mycobacterium tuberculosis from Prison Populations in Santa Catarina, Southern Brazil.

[5] PATI 5 (2014) Guide for the Management of Tuberculosis, Kinshasa, Congo. 10.

[6] Pichard, D.E. et al. (2002) Tuberculosis: Infectious Diseases. FMPOS.

[7] National Tuberculosis Control Program (2015) National Directives, MSP, Kinshasa, DRC.

[8] Okenge. L. (2009) Prevalence of Tuberculosis in the City of Kinshasa, DRC.

[9] Hill, P.C., Stevens, W., Hill, V., Bah, J., Donkor, S.A., Jallow, A. and Lienhardt, C. (2005) Risk Factors for Discontinuing Treatment for Tuberculosis: A Prospective Cohort Study of 301 Cases in The Gambia. The International Journal of Tuberculosis and Lung Disease, 9, 1349-1354.

[10] Mouhi, I. (2016) Paucibacillary Tuberculosis, Where Are We? 6-Year Retrospective Study in the Khenifra Region. Thesis Presented and Defended at the Faculty of Medicine and Pharmacy, Sidi Mohammed ben Abdellah University, Mali.

[11] M’boussa, J., Martins, H., Adicolle-Metoul, J.M. and Loubaki, F. (1999) The Influence of Socio-Cultural Factors on Discontinuation of Pulmonary Tuberculosis Treatment. Black African Medicine, 46, 458-465.

[12] Hassani, L. (2010) Factors Involved in the Abandonment of Anti-Bacillary Treatment in Patients with Pulmonary Tuberculosis with Positive Microscopy (Case of the Prefectures Ain Chock-Hay Hassani-Nouaceur). Master's Thesis, Health Administration of Public Health, Health Services Management Stream. National Institute of Sanitary Administration, Morocco.

[13] Julio Rakotonirina, L.J., Ravaoarisoa, L., Randriatsarafara, F.M., de Dieu Marie Rakotomanga, J. and Robert, A. (2009) Factors Associated with the Discontinuation of Anti-Tuberculosis Treatment in the City of Antananarivo, Madagascar. SFSP Public Health, 21, 139-146. https://doi.org/10.3917/spub.092.0139 https://www.cairn.info/revue-sante-publique-2009-2-page-139.htm

[14] Habibi, B., Atmane, A., Hammi, S., Bourkadi, J., Marc, K., Soualhi, M., Zehraoui, R. and Benamor, J. (2016) Risk Factors for Discontinuation of Anti-Bacillary Treatment in Patients with Microscopic Positive Pulmonary Tuberculosis (TPM+). Journal of Respiratory Diseases, 33, A42-A43. https://doi.org/10.1016/j.rmr.2015.10.667 